\title{
Silencing IDO2 in dendritic cells: A novel strategy to strengthen cancer immunotherapy in a murine lung cancer model
}

\author{
YANLING LIU $^{1}$, PING XU ${ }^{1}$, HUAN LIU ${ }^{1}$, CHUNJUAN FANG $^{1}$, HAIHE GUO ${ }^{1}$, \\ XIAOYAN CHEN ${ }^{1}$, MANMAN TAN ${ }^{2}$, YUJUAN ZHANG ${ }^{2}$ and WEIPING MIN ${ }^{2,3}$ \\ ${ }^{1}$ Medical Laboratory, Jiangxi University of Technology; ${ }^{2}$ Institute of Immunotherapy, Nanchang University and \\ Jiangxi Academy of Medical Science, Nanchang, Jiangxi 330098, P.R. China; ${ }^{3}$ Department of Surgery, \\ Pathology and Oncology, University of Western Ontario, London, Ontario N6A 5A5, Canada
}

Received November 19, 2019; Accepted May 6, 2020

DOI: $10.3892 /$ ijo.2020.5073

\begin{abstract}
While dendritic cell (DC)-based immunotherapy has achieved satisfactory results in animal models, its effects were not satisfactory as initially expected in clinical applications, despite the safety and varying degrees of effectiveness in various types of cancer. Improving the efficacy of the DC-based vaccine is essential for cancer immunotherapy. The present study aimed to investigate methods with which to amplify and enhance the antitumor immune response of a DC-based tumor vaccine by silencing the expression of indoleamine 2,3-dioxygenase 2 (IDO2), a tryptophan rate-limiting metabolic enzyme in DCs. In vitro experiments revealed that the silencing of IDO2 in DCs did not affect the differentiation of DCs, whereas it increased their expression of costimulatory molecules following stimulation with tumor necrosis factor (TNF)- $\alpha$ and tumor lysate from Lewis lung cancer (LLC) cells. In a mixed co-culture system, the IDO2-silenced DCs promoted the proliferation of T-cells and reduced the induction of regulatory T-cells (Tregs). Further in vivo experiments revealed that the silencing of IDO2 in DCs markedly suppressed the growth of tumor cells. Moreover, treatment with the IDO2-silenced DC-based cancer vaccine enhanced cytotoxic $\mathrm{T}$ lymphocyte activity, whereas it decreased T-cell apoptosis and the percentage of $\mathrm{CD} 4^{+} \mathrm{CD} 25^{+} \mathrm{Foxp} 3^{+}$Tregs. On the whole, the present study provides evidence that the silencing of the tryptophan rate-limiting metabolic enzyme,
\end{abstract}

Correspondence to: Professor Weiping Min, Department of Surgery, Pathology and Oncology, University of Western Ontario, 339 Windermere Road, LHSC-UH B4-232, London, Ontario N6A 5A5, Canada

E-mail: weiping.min@uwo.ca

Abbreviations: IDO2, indoleamine 2,3-dioxygenase 2; DCs, dendritic cells; siRNA, small interfering RNA; GL2, luciferase gene duplex; CFSE, 5(6)-carboxyfluorescein diacetate $\mathrm{N}$-succinimidyl ester; LLC, Lewis lung cancer; CTL, cytotoxic T lymphocyte

Key words: dendritic cells, siRNA, IDO2, immunotherapy, lung cancer
IDO2, has the potential to enhance the efficacy of DC-based cancer immunotherapy.

\section{Introduction}

Cancer cells have the ability to evade or escape immune monitor and destruction, which leads to carcinogenesis and cancer progression (1). Immunosuppression and evasion can be mediated via a variety of mechanisms, such as interleukin (IL)-10 or transforming growth factor (TGF)- $\beta$ induced Th2 polarization (2-5), the overexpression of Fas ligand/TRAIL (6,7), the overexpression of complement inhibitors (DAF and CD55) (8), the loss of MHC class I molecules or tumor antigens, as well as the overexpression of indoleamine 2,3-dioxygenase (IDO), a tryptophan catabolizing enzyme (9-13). It has been demonstrated that tryptophan catabolism by IDO1 mediates a mechanism that suppresses T-cells, providing balance or feedback control in immune reactions $(14,15)$. Over the past decade, a novel immunosuppression factor, namely the tryptophan catabolizing enzyme, IDO2, has attracted attention and has stimulated research in tumor and autoimmune diseases (16). IDO2 and IDO1 are homologous proteins and they are arranged in tandem on the same chromosome. Similar to the classical immunosuppression enzyme IDO1, IDO2 can degrade tryptophan, although it's the efficiency is less than that of IDO1 (17-19). Previous studies have demonstrated their similar functions in the immune system. It has been reported that IDO2 is expressed in dendritic cells (DCs) $(17,20)$ and that IDO2 is expressed in peripheral blood DCs by a steady-state model and may contribute to the homeostatic tolerogenic capacity of DCs under healthy conditions (21). IDO2 gene-transfected 293 cells have been shown to inhibit $\mathrm{CD}^{+}$and $\mathrm{CD}^{+} \mathrm{T}$-cell proliferation in a co-culture system (18). Additionally, IDO2 is critical for IDO1-mediated T-cell regulation and performs a non-redundant function in inflammation (22).

DCs are antigen-presenting cells, forms key link between the innate and adaptive immune responses and play a pivotal role in the initiation of the immune response. Due to their unique ability, DCs attract interest in tumor immunotherapy and vaccine development. The activation of DCs is essential for the stimulation of immunity. It has been demonstrated in vitro 
and in vivo that DCs loaded with tumor antigens (ex vivo) successfully induce the activity of cytotoxic T-cells against tumor cells in animal models or clinical trials (23-25). In previous studies, the authors successfully developed IDO-siRNA based antitumor therapeutics through the direct knockdown of IDO in mice with tumors (26-28) or using IDO-silenced DCs as antitumor vaccines $(29,30)$. However, role of IDO2 in DC-mediated antitumor immunity has not yet been studied, at least to the best of our knowledge. In view of the role of IDO2 in immunosuppression, it was hypothesized that the silencing of IDO2 in DCs would activate the DCs to enhance the antitumor response and furthermore, to suppress tumor progression.

In the present study, the potent gene silencing method was applied to knock down IDO2 expression in DCs. In ex vivo experiments, it was demonstrated that the silencing of IDO2 promoted DCs maturation, which elicited strong T-cell responses. Using a murine lung cancer model, it was found that the IDO2-silenced DC-based cancer vaccine effectively suppressed tumor growth and enhanced the antitumor immune response in vivo. To the best of our knowledge, this is the first study to report the role of IDO2 in DCs in a murine lung cancer model. The IDO2-silenced DC-based cancer vaccine may thus prove to be a novel potent cancer therapy through the depletion of immune suppression and the reinstallation of anticancer immunity.

\section{Materials and methods}

Animals and cancer cell lines. A total of 80 female C57/BL6 mice and 20 female BABL/C mice (6 to 8 weeks old, weighing 18-22 g) were purchased from Changsha Laboratory Animal Co. Ltd. All the mice were kept in a specific pathogen-free grade environment, without dietary restrictions, at a temperature of $25 \pm 2{ }^{\circ} \mathrm{C}$ and $60 \pm 5 \%$ air relative humidity. All animal experiments complied with the Regulations for the Administration of Affairs Concerning Experimental Animals of China and ethics approval was obtained from the Institutional Animal Care and Use Committee of Nanchang University. The LLC cell line was purchased from the China Center for Type Culture Collection (CCTCC) and cultured in DMEM (Invitrogen, Life Technologies; Thermo Fisher Scientific, Inc.) containing 10\% FBS, L-glutamine, penicillin and streptomycin in $5 \% \mathrm{CO}_{2}$ and at $37^{\circ} \mathrm{C}$.

Generation of C57BL/6 bone marrow-derived DCs. DCs were generated from C57BL/6 bone marrow progenitor cells as previously described (31). Briefly, the femurs of mice were removed and the marrow cavity was flushed with RPMI-1640 medium (Gibco; Thermo Fisher Scientific, Inc.) to obtain bone marrow progenitor cells. After washing with RPMI-1640 medium twice, the obtained cells were plated in 6-well tissue culture plates. Each well was supplemented with $4 \mathrm{ml} \mathrm{DC}$ induction medium which contained RPMI-1640 medium, 10\% FBS (Gibco; Thermo Fisher Scientific, Inc.), 10 ng/ml recombinant murine IL-4 and $10 \mathrm{ng} / \mathrm{ml}$ granulocyte-macrophage colony-stimulating factor (GM-CSF; PeproTech, Inc.). The induced cells were maintained at $37^{\circ} \mathrm{C}$ in $5 \%$ humidified $\mathrm{CO}_{2}$ and the medium was replaced with new DC induction medium described above every 2 days.
Synthesis of IDO2 siRNA and gene silencing. The siRNA targeting murine IDO2 mRNA was designed in accordance with the target sequence selection method and synthesized by the manufacturer (Sigma-Aldrich; Merck KGaA). GL2 siRNA targeting the luciferase gene was used as the control siRNA. IDO2 (5'-GUCAUGUCCUGCACCCUAA-3') and GL2 (5'-GCAUGCGCCUUAUGAAGCU-3') siRNAs were transfected into the DCs using Lipofectamine2000 reagent (Invitrogen; Thermo Fisher Scientific, Inc.). Briefly, the cells were collected, centrifuged $(1,000 \mathrm{x} \mathrm{g})$ for $5 \mathrm{~min}$, resuspended in Opti MEM ${ }^{\circledR}$ serum-reduced medium (Invitrogen, Life Technologies; Thermo Fisher Scientific, Inc.) and then plated in 12 -well plates $\left(2 \times 10^{6}\right.$ cells/well). A total of $1 \mu \mathrm{g}$ IDO2- or GL2-siRNA was incubated with $2 \mu$ l Lipofectamine 2000 reagent in $200 \mu \mathrm{l}$ of optimal serum-reduced medium at room temperature for $20 \mathrm{~min}$ and the mixture was then gently added to the cells in each group.

IDO2 mRNA quantification by RT-qPCR. DCs were collected, lysed and total RNA was extracted according to the manual of manufacturer (TRIzol reagent; Invitrogen; Thermo Fisher Scientific, Inc.). Total RNA $(1 \mu \mathrm{g})$ was used as a template to synthesize cDNA by reverse transcriptase (MMLV-RT, Invitrogen; Thermo Fisher Scientific, Inc.). qPCR were conducted using a Stratagene Mx3000P QPCR System (Agilent Technologies, Inc.) and 2X SYBR-Green PCR Master Mix (Life Technologies; Thermo Fisher Scientific, Inc.) was used to perform the reactions according to manufacturer's protocol. The PCR thermocycling conditions were as follows: Denaturation for $2 \mathrm{~min}$ at $95^{\circ} \mathrm{C}$, followed by 44 cycles of denaturation for $10 \mathrm{sec}$ at $95^{\circ} \mathrm{C}$, and extension for $20 \mathrm{sec}$ at $58^{\circ} \mathrm{C}$. The following primer sequences were used for target gene amplifications: IDO2 forward, 5'-GTGGGGCTGGTCTATGAAGGTG-3' and reverse, 5'-TGGTGGCAGCGGAGATAATGTA-3'; IDO1 forward, 5'-GGGCTTTGCTCTACCACATCCACT-3' and reverse, 5'-ACATCGTCATCCCCTCGGTTCC-3'; and GAPDH forward, 5'-TGATGACATCAAGAAGGTGGTGAA-3' and reverse, 5'-TCCTTG GAGGCCATGTAGGCCAT-3'. Differences in gene expression were calculated using the $\Delta \Delta \mathrm{Cq}$ method (32).

Western blot analysis. The cells were collected, washed twice with PBS, and re-suspended in iced RIPA buffer (Cell Signaling Technology, Inc.) for $30 \mathrm{~min}$. Lysates were centrifuged $(20,000 \mathrm{x} \mathrm{g})$ for $30 \mathrm{~min}$ at $4^{\circ} \mathrm{C}$ to obtain the total protein. A total of $50 \mu \mathrm{g}$ of total protein was then separated on a $12 \%$ SDS-PAGE and transferred to a nitrocellulose membrane. To reduce background intensity, $5 \%$ fat-free milk in TBS-T $(0.25 \%$ Tween-20) was used to block the membrane. To probe the target protein, the blocked membranes were incubated with a rabbit anti-mouse IDO2 monoclonal antibody (cat. no. sc-374159, 1:500, clone C-9, Santa Cruz Biotechnology, Inc.) or $\beta$-actin (cat. no. sc-58673, 1:5,000, clone 2Q1055, Santa Cruz Biotechnology, Inc.) overnight at $4^{\circ} \mathrm{C}$. Following incubation, the membrane was washed with PBST for 3 times and then incubated with a mouse anti-rabbit IgG-HRP antibody (sc-2357, 1:5,000, Santa Cruz Biotechnology, Inc.) for $1.5 \mathrm{~h}$ at room temperature. The ECL system was used for membrane color rendering (GE Healthcare). 
Flow cytometry. Flow cytometry was used to analyze the characterization of DCs and the induction of regulatory T-cells (Tregs) in vitro. DCs were harvested and stained with FITC-CD11c mAb (cat. no. MA5-16877, clone N418), PE-CD80 mAb (cat. no. 12-0801-82, clone 16-10A1), PE-CD86 $\mathrm{mAb}$ (cat. no. 12-0862-82, clone GL1) and Pe-Cy5-CD40 mAb (cat. no. 15-0401-82, clone 1C10) (eBioscience; Thermo Fisher Scientific, Inc.) for $30 \mathrm{~min}$ at $4^{\circ} \mathrm{C}$. For Treg subsets analyzing, the cells were stained with FITC-Foxp3 mAb (cat. no. 11-5773-82, clone FJK-16s), PE-CD4 mAb (cat. no. 12-0041-82, clone GK1.5) and PeCy5-CD25 mAb (cat. no. 15-0251-82, clone PC61.5) (eBioscience; Thermo Fisher Scientific, Inc.) for $30 \mathrm{~min}$ at $4^{\circ} \mathrm{C}$. Flow cytometry was also used to determine the apoptosis of T-cells and subsets of regulatory T-cells from the tumor-draining lymph nodes or spleen from the tumor-bearing mice in vivo. To explore cell apoptosis of $\mathrm{T}$ cells, PE-CD4 $\mathrm{mAb}$ or PeCy5-CD8 mAb (cat. no. 15-0081-82, clone 53-6.7) (eBioscience; Thermo Fisher Scientific, Inc.) were used to pre-stained the T-cells for $30 \mathrm{~min}$ at $4^{\circ} \mathrm{C}$ and then stained with FITC-Annexin V (BD Pharmingen) for $5 \mathrm{~min}$ at $4^{\circ} \mathrm{C}$. All cells were examined using a BD FACSCalibur flow cytometer (BD Biosciences) and the results were analyzed using FlowJo software (Tree Star, Inc.).

Mixed lymphocyte reaction (MLR) and Treg induction. T-cells from the lymph nodes of naïve BALB/c mice were used to perform the allogeneic MLR and Treg induction. Briefly, the lymph nodes of mice were collected and paced on 6-well plate which contains a 200 mesh screen strainer and 2 ml RPMI-1640 medium and then grinded, purified and enriched using nylon wool columns. T-cells were labeled with 5(6)-carboxyfluorescein diacetate $\mathrm{N}$-succinimidyl ester (CFSE) (eBioscience; Thermo Fisher Scientific, Inc.) for mixed lymphocyte reaction, while the unlabeled cells were used for Treg induction. IDO2-siRNA- or GL2-siRNA-transfected DCs $\left(1 \times 10^{5}\right)$ and T-cells $\left(1 \times 10^{6}\right)$ were co-cultured in 24 -well plates. The mixed lymphatic reaction lasted for 3 days and Treg induction lasted for 5 days. The proliferation of T-cells (using CFSE) and $\mathrm{CD} 4{ }^{+} \mathrm{CD} 25^{+} \mathrm{Foxp}^{+}$Tregs was analyzed by flow cytometry using a BD FACSCalibur flow cytometer (BD Biosciences).

Preparation of IDO2-silenced DC vaccine. The in vitro induced DCs were transfected with IDO2- or GL2 (control)-siRNA on day 5 of culture. To prepare tumor antigen, the mouse LLC lung cancer cells were dissolved using a 6-cycle freeze-thaw method and then centrifuged $(20,000 \mathrm{x} \mathrm{g})$ for $30 \mathrm{~min}$ at $4^{\circ} \mathrm{C}$ to obtain the total tumor antigen. The LLC lysate $(50 \mathrm{ng} / \mathrm{ml})$ was added to the culture medium following transfection and kept for $24 \mathrm{~h}$ to allow the loading of lung cancer antigen by DCs. Antigen-pulsed DCs were stimulated to mature using tumor necrosis factor (TNF)- $\alpha$ (20 ng/ml, PeproTech, Inc.) overnight. The IDO2-silenced or control, antigen-loaded mature DCs were collected for used in the following in vivo experiments.

Treatment with IDO2-silenced DC vaccine. In order to examine the antitumor effect of the vaccine in vivo, C57/BL6 mice were used to establish a lung cancer model, and were grouped as follows: Healthy mice, tumor mice with sham treatment, tumor mice untreated with control DCs and IDO2-silenced DCs. Each group contained 4 mice and the experiment was repeated 3 times. LLC cells $\left(5 \times 10^{5}\right.$ cells in $100 \mu \mathrm{l}$ cell suspension) were subcutaneously injected into the upper hind leg of each mouse. The tumor-bearing mice were treated with $1 \times 10^{6}$ of the IDO2-silenced or control DC vaccine from day 3 of LLC cell inoculation, once every 5 days for 4 times. The tumor diameter was measured using a caliper every other day when tumors appeared. The tumor volumes were calculated using the following formula: Tumor volume $\left(\mathrm{mm}^{3}\right)=$ width $(\mathrm{mm})^{2} \mathrm{x}$ length $(\mathrm{mm}) \times 0.5$.

Cytotoxic T lymphocyte (CTL)-mediated tumor cell lysis assay. The cytotoxicity of $\mathrm{CD}^{+} \mathrm{T}$-cells from DC-treated tumor bearing mice was analyzed using a nonradioactive cytotoxicity assay kit (Promega Corp.), in order to determine the tumor-specific lysis against lung cancer cells. Briefly, $\mathrm{CD} 8^{+} \mathrm{T}$-cells were isolated from the draining lymph nodes of tumor-bearing mice using immunomagnetic beads (Miltenyi Biotec). The target tumor cells (105 LLCs) were incubated with the $\mathrm{CD}^{+} \mathrm{T}$-cells at a ratio of 1:25, 1:50 and 1:100 for $4 \mathrm{~h}$ and the supernatant was then collected for the measurement of lactate dehydrogenase (LDH) using a coupled enzymatic assay. The intensity of the color indicated the number of lysed cells. The cytotoxic activity of CTL $(\%)=[($ absorbance OD) - (spontaneous effector cell LDH release OD) - (spontaneous target cell LDH release OD)]/[(maximal LDH release OD) (spontaneous target cell LDH release OD)] x100\%.

Cytokine secretion assay. The tumor-bearing mice treated with the different DC vaccines were anesthetized by an intraperitoneal injection of chloral hydrate $(400 \mathrm{mg} / \mathrm{kg})$ and then blood was obtained by cardiac puncture. The death of the mice was judged by the absence of corneal reflex, heartbeat and respiration for $>5 \mathrm{~min}$. The blood was placed in a micro-centrifuge tube at room temperature for half an hour and then centrifuged $(3,000 \mathrm{x} \mathrm{g})$ for $20 \mathrm{~min}$ at room temperature. Serum was collected from the upper layer of the blood using a pipette, removed to another clean micro-centrifuge tube at and stored in a storage freezer $\left(-80^{\circ} \mathrm{C}\right)$ for use in following experiments. ELLSA kits (eBioscience; Thermo Fisher Scientific, Inc.) were used to detect the levels of interferon (IFN) $-\gamma$, TNF- $\alpha$, IL-10 and TGF- $\beta$ in serum according to the manufacturer instructions.

Statistical analysis. Data are presented as the means \pm SD. The Student's t-test (2-tailed) was used to determine differences between 2 means. Differences between multiple groups were analyzed by one-way ANOVA, followed, if necessary, by Tukey's test ( $\geq 3$ groups). For all statistical analyses, P-values $<0.05$ were considered to indicate statistically significant differences.

\section{Results}

expression of IDO2 in DCs. The expression of IDO1 in DCs has a potent immunosuppressive effect and can induce Tregs in the microenvironment (14). IDO2, a homologous protein of IDO1, is expressed in human myeloid and plasma-like DCs, which can induce Treg cell production in vitro (21). However, the tendency of IDO2 expression during the maturation of DCs has not yet been reported, at least to the best of our 
A

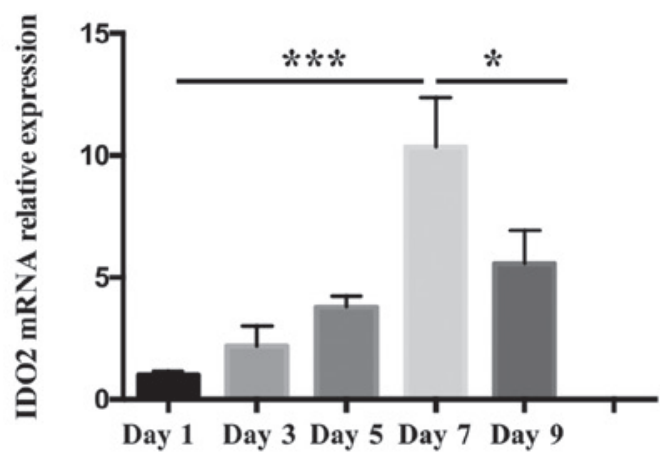

C

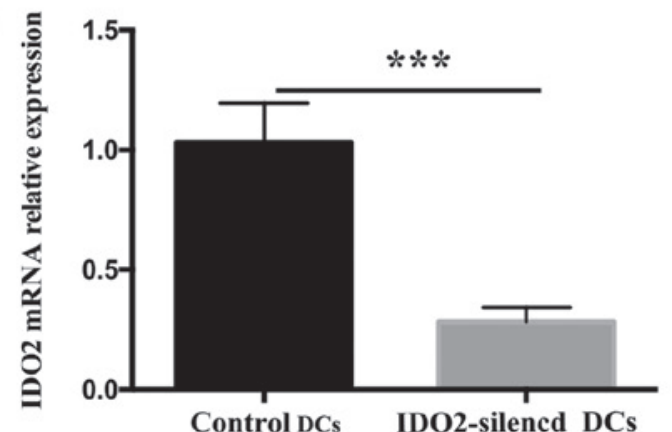

B

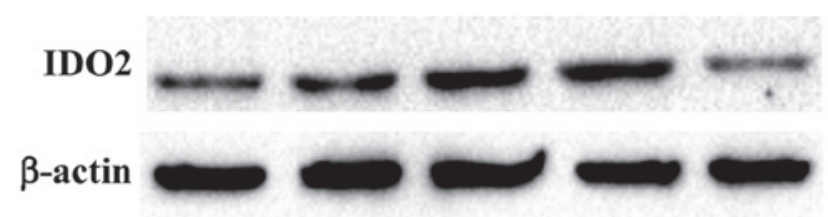

Day 1 Day 3 Day 5 Day 7 Day 9
D

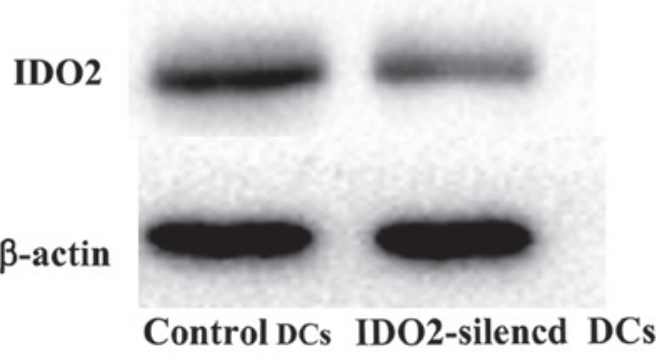

Figure 1. IDO2 expression in DCs. (A and B) Change in IDO2 expression in the progression of DC culture. C57BL/6 bone marrow-derived DCs were induced with IL-4 (10 ng/ml) and GM-CSF (10 ng/ml) for 9 days. The change in IDO2 (A) mRNA or (B) protein expression was detected by RT-qPCR and western blot analysis, respectively, assessed on every other day. (C and D) siRNA-mediated IDO2 gene silencing in DCs. siRNAs targeting IDO2 or GL2 (control siRNA) were transfected into the bone marrow-derived DCs using Lipofectamine 2000 on day 5 of culture. At $48 \mathrm{~h}$ following transfection, the effectiveness of the gene silencing of IDO2 was detected by (C) RT-qPCR and (D) western blot analysis. ${ }^{*} \mathrm{P}<0.05$ and ${ }^{* * *} \mathrm{P}<0.001$. IDO2, indoleamine 2,3 -dioxygenase 2; DCs, dendritic cells; IL-4, interleukin 4; GM-CSF, granulocyte-macrophage colony-stimulating factor.

knowledge. Therefore, the present study first investigated the changes occurring in IDO2 expression during DC maturation. To determine the IDO2 expression level, bone marrow-derived DCs were induced and total RNA or protein was collected every other day. As shown in Fig. 1A, the transcriptional level of IDO2 increased gradually during DC culture, reaching peak levels on the 7th day, and then decreasing. At the same time, the change in the IDO2 protein level was also detected (Fig. 1B). The results revealed that the change in protein expression was consistent with that observed for mRNA expression.

In order to examine the role of IDO2 in bone marrow-derived DCs, siRNA technology was used for gene silencing. To determine the siRNA efficacy, the DCs were transfected with Lipofectamine 2000 coated with IDO2-siRNA or GL2-siRNA (control siRNA). Following $48 \mathrm{~h}$ of transfection, the expression of IDO2 mRNA decreased significantly and the silencing efficiency was $>70 \%$ (Fig. 1C). The silencing effect was further determined by western blot analysis to determine protein level of IDO2 (Fig. 1D). The results of both RT-qPCR and western blot analysis revealed that IDO2-siRNA was effective in knocking down the expression of IDO2 in bone marrow-derived DCs.

Effect of IDO2 gene silencing on DC phenotype and maturation. Immunologically competent mature DCs are the most efficient antigen-presenting cells (APCs). Upon stimulation with antigen, the phenotype of DCs changes from an immature status to mature APCs and activates T-cell proliferation (33). In the present study, to investigate the role of IDO2 in the maturation of DCs, bone marrow-derived DCs were transfected with IDO2-siRNA or GL2 (control)-siRNA as presented in Fig. 1, followed by the assessment of DC maturation markers. As shown in Fig. 2, although IDO2 gene silencing did not affect the expression of CD11c, CD80, CD86 and CD40 on the surface of DCs, it significantly increased the percentage of mature DCs following treatment with $\mathrm{TNF}-\alpha$ or $\mathrm{TNF}-\alpha$ plus tumor antigen. These data suggest that IDO2 gene silencing can enhance the sensitivity of DCs to TNF- $\alpha$ and tumor antigen, which can promote DC maturation.

IDO2 gene silencing in DCs enhances the T-cell response and reduces Treg induction. As previously demonstrated, IDO2 gene transfected into 293 cells can inhibit the $\mathrm{CD}^{+}$and $\mathrm{CD}^{+}$ T-cell proliferation in a co-culture system (18). Therefore, the present study investigated whether IDO2-silenced DCs may affect the stimulation of T-cell proliferation. To evaluate the capacity of DCs to stimulate T-cell responses following the gene silencing of IDO2, mixed leukocyte reaction was performed. DCs cultured from C57BL/6 mice were transfected with IDO2-siRNA, or GL2-siRNA as the control. The results revealed that compared to transfection with the control siRNA, IDO2 gene silencing in the DCs initiated a potent T-cell response (Fig. 3A). The potential for gene silencing of IDO2 to alter the Treg induction by DCs was then determined. The IDO2-silenced DCs were co-cultured with naïve allogeneic T-cells for 5 days. The percentage of $\mathrm{CD}^{+}{ }^{+} \mathrm{CD} 25^{+} \mathrm{Foxp}^{+}$ 
A

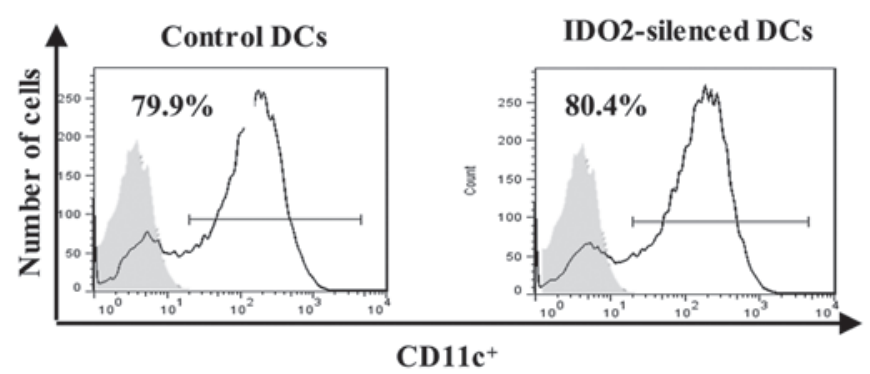

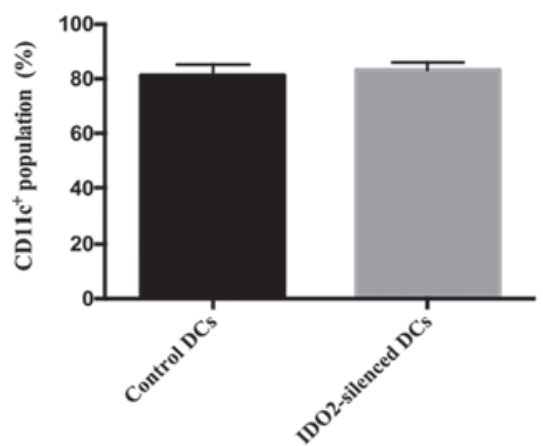

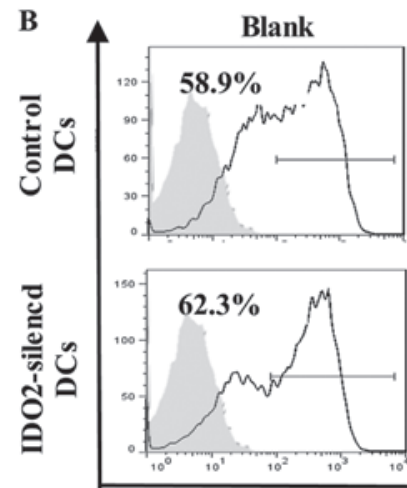

TNF- $\alpha$
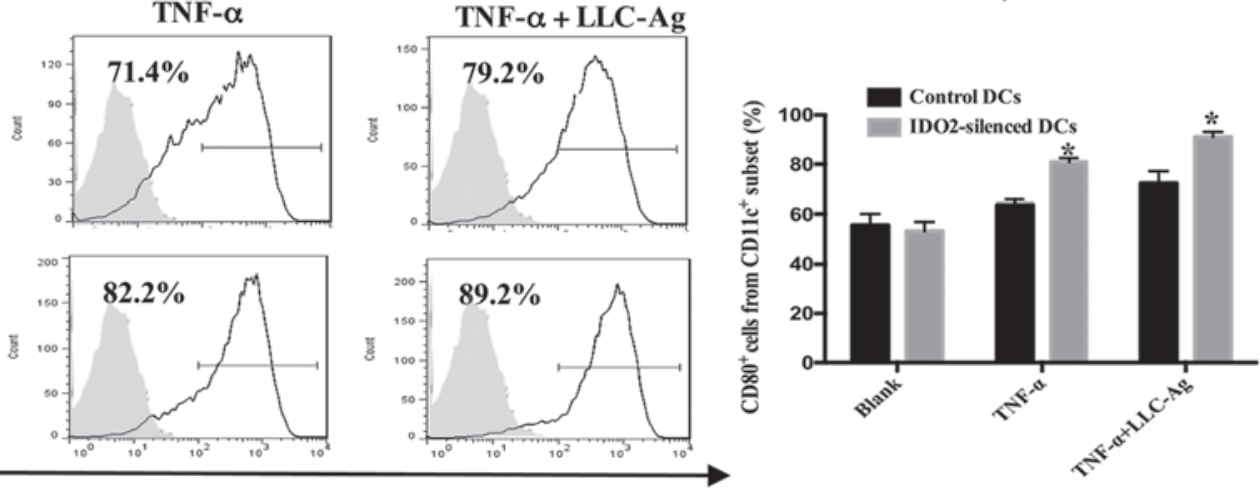

$\mathrm{CD80}^{+}$

C
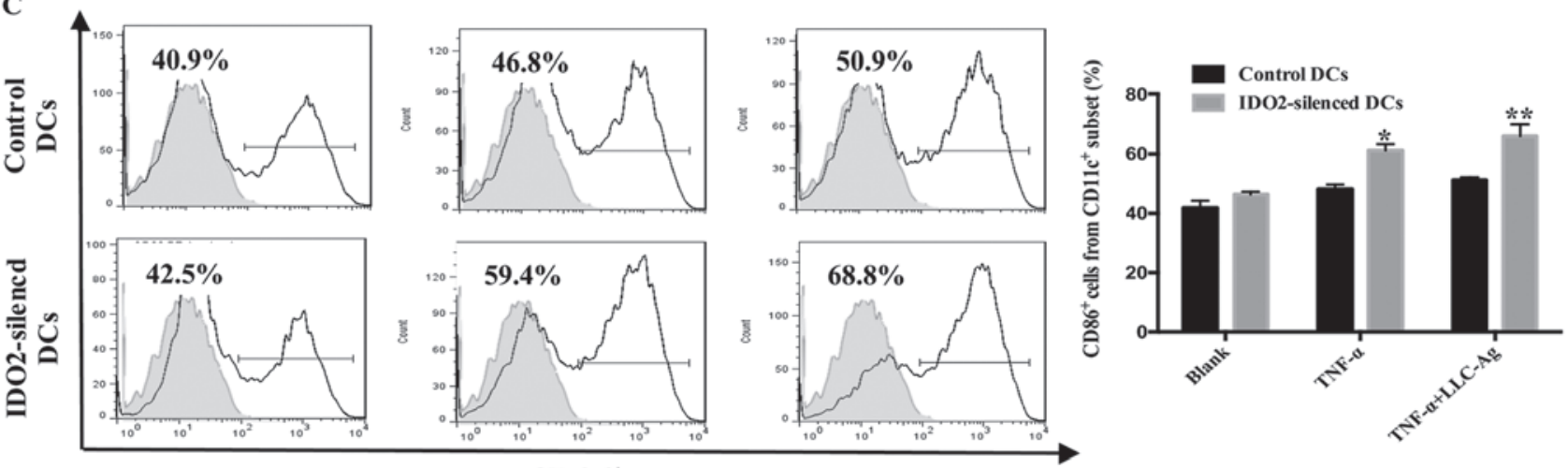

CD86 $^{+}$
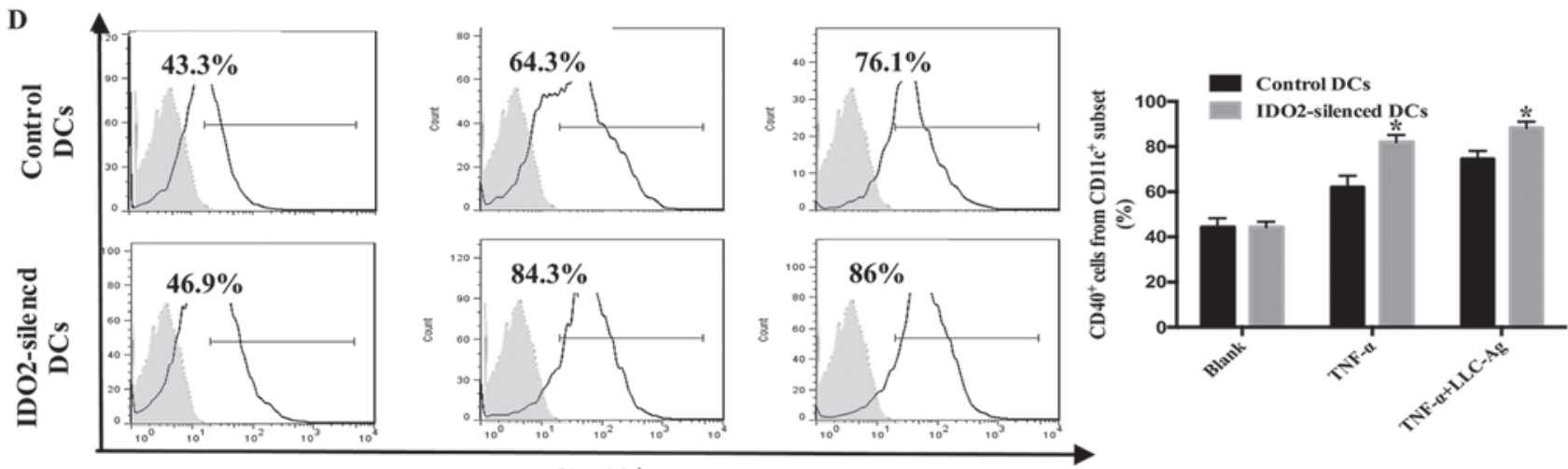

$\mathrm{CD}^{+} 0^{+}$

Figure 2. Effect of IDO2 gene silencing on DC maturation. Bone marrow-derived DCs were cultured and transfected with IDO2 or GL2 (control) siRNA as described in the legend of Fig. 1. DCs matured with TNF- $\alpha$ or TNF- $\alpha$ plus LLC-Ag, respectively for $24 \mathrm{~h}$ on day 6 and flow cytometry were used to assessed the DC phenotype on day 7. DC differentiation was determined by (A) FITC-CD11c, (B) PE-CD80, (C) PE-CD86 and (D) PE-cy5-CD40. "P<0.05 and "P<0.01, compared to control DCs. IDO2, indoleamine 2,3-dioxygenase 2; DCs, dendritic cells; TNF- $\alpha$, tumor necrosis factor $\alpha$.

Tregs was significantly decreased when the T-cells incubated with IDO2-silenced DCs, as compared with that of the cells incubated with control DCs (Fig. 3B).
Administration of IDO2-silenced DCs suppresses tumor progression. To evaluate the therapeutic efficacy of IDO2-silenced DCs in lung cancer, IDO2-siRNA- or 
A
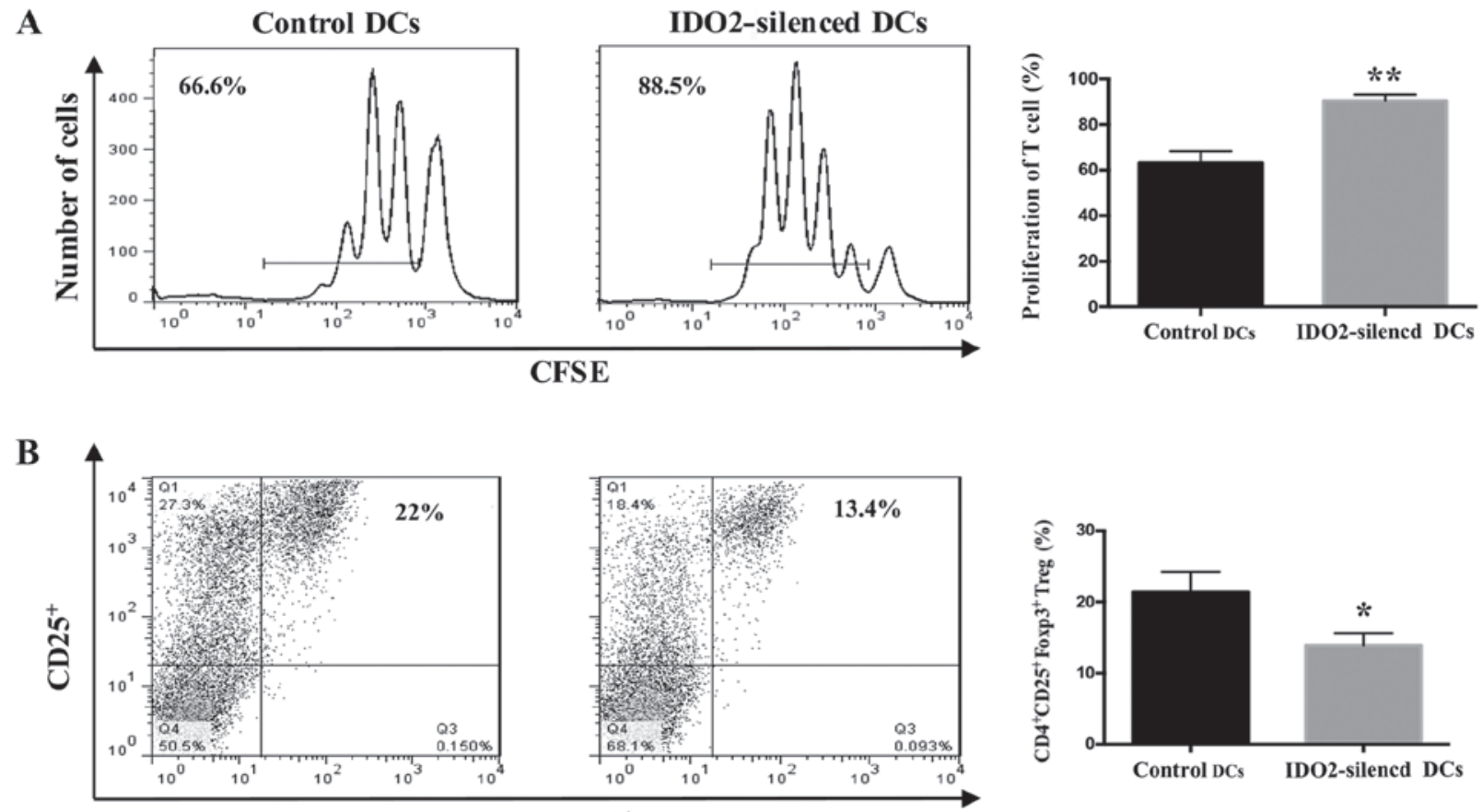

Foxp3 $^{+}$

Figure 3. Effect of IDO2 gene silencing on the T-cell response. DCs were transfected with IDO2-siRNA or control siRNA (GL2) on day 5 and harvested on day 7. Mixed lymphocyte reaction was carried out to detect the DC function on T-cell proliferation and induction of Tregs. Allogeneic BALB/c mouse-derived T-cells were first labeled with CFSE, then co-cultured with DCs at a ratio of 10:1. (A) The proliferation of T-cells was detected by flow cytometry $72 \mathrm{~h}$ later. Effect of IDO2 gene silencing in DCs on (B) Treg induction was analyzed by flow cytometry 5 days later. "P $<0.05$ and ${ }^{* *} \mathrm{P}<0.01$, compared to control DCs. IDO2, indoleamine 2,3-dioxygenase 2; DCs, dendritic cells; CFSE, 5(6)-carboxyfluorescein diacetate N-succinimidyl ester.

A

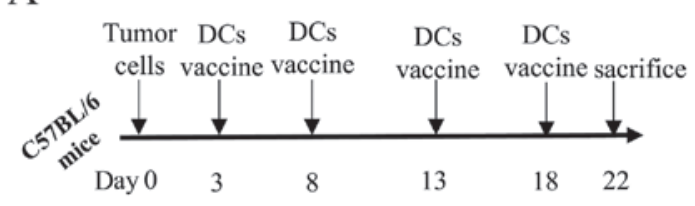

$\mathrm{C}$

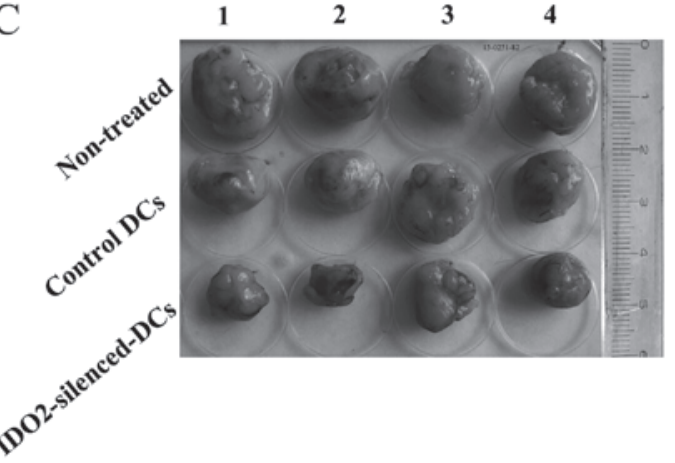

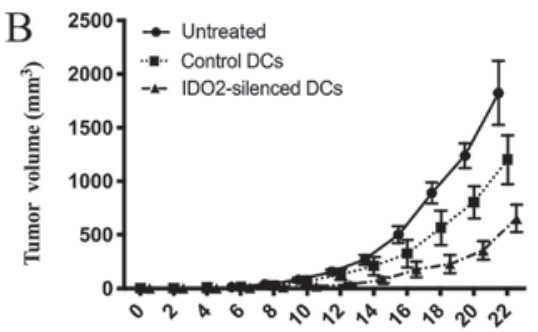

$\mathrm{D}$

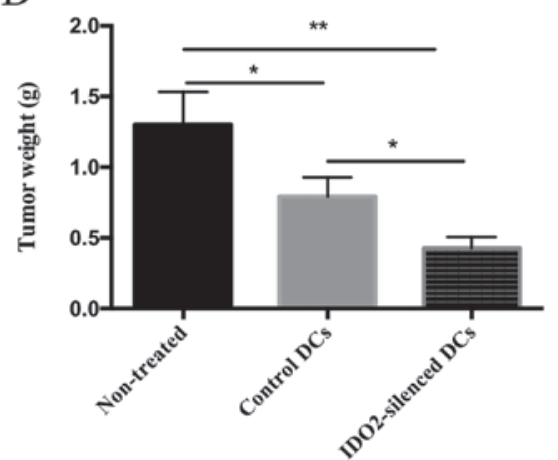

Figure 4. Administration of IDO2-silenced DC tumor vaccine suppresses tumor progression. (A) LLC $\left(2 \times 10^{5}\right)$ cells were injected into the upper hind legs of C57BL/6 mice subcutaneously ( $\mathrm{n}=4$ /group, repeat 3 times). The tumor-bearing mice treatment with the DC-based tumor vaccine received 4 times by intravenous injection. Untreated mice served as the blank control. Tumor diameter was measured using a Vernier caliper every other day. Tumor-bearing mice were sacrificed on day 22 and the tumors were excised, and (C) photographed, and (B) tumor volume and (D) weight were determined. ${ }^{*} \mathrm{P}<0.05$ and ${ }^{* *} \mathrm{P}<0.01 . \mathrm{IDO} 2$, indoleamine 2,3-dioxygenase 2; DCs, dendritic cells.

GL2-siRNA-transfected DCs were loaded with lysates of LLC cells, and subsequently used to treat mice inoculated with LLC tumors. According to the tumor growth curve and tumor images, the tumors of untreated mice were larger and the length of largest tumor was approximately $19 \mathrm{~mm}$ and the diameter was approximately $15 \mathrm{~mm}$. (volume, $19 \times 15 \times$ $15 \times 0.5=2,137.5 \mathrm{~mm}^{3}$ ). Compared to the untreated mice, the two DC vaccines inhibited tumor growth, although the 
A

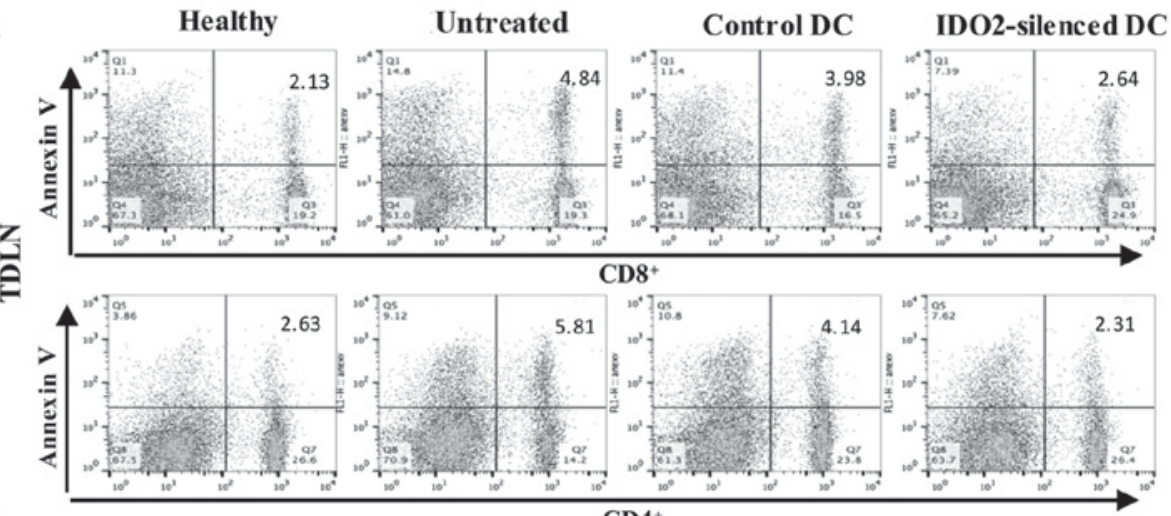

Untreated

B
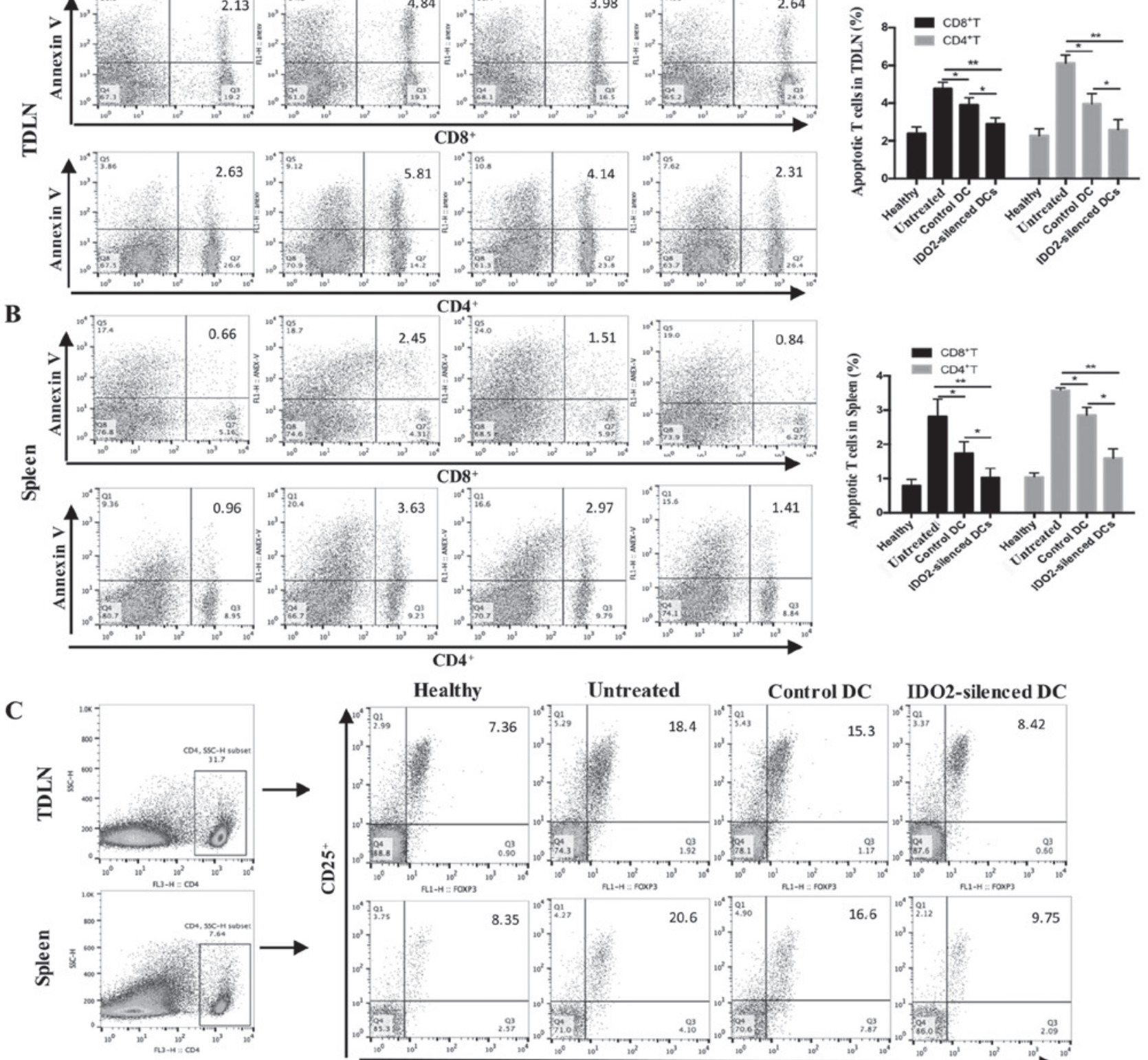

D
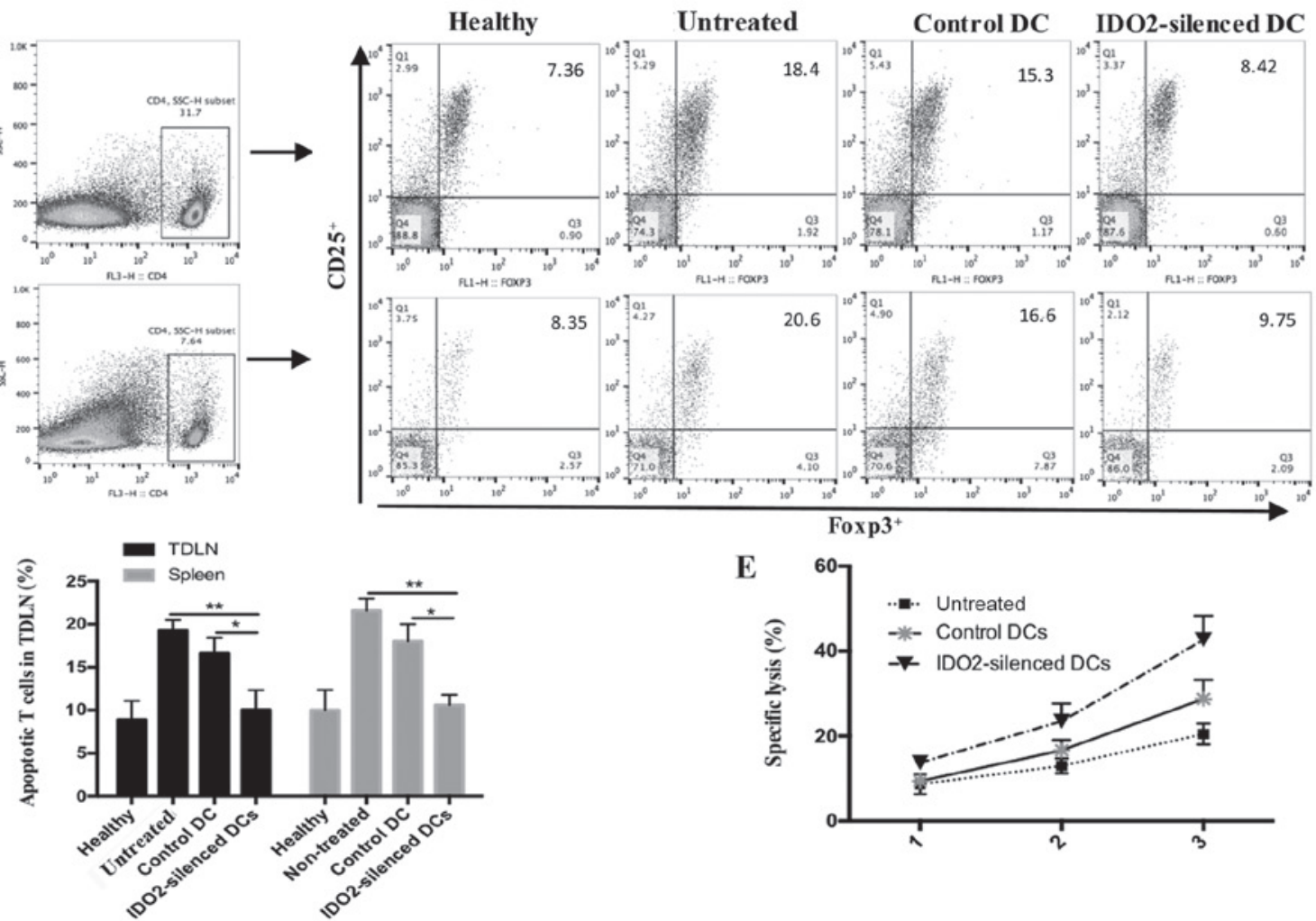

Foxp3 $^{+}$

E

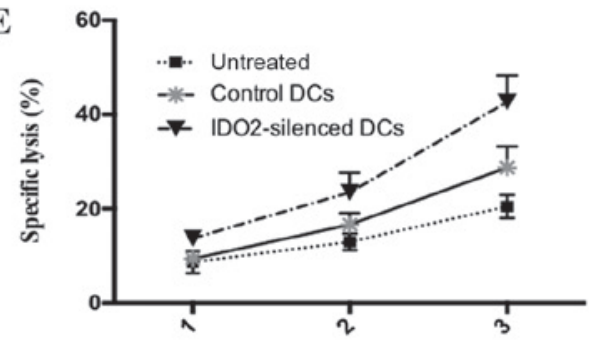

Figure 5. IDO2-silenced DC tumor vaccine enhances the antitumor immune response. C57BL/6 mice were inoculated with LLC cells and treated with the DC vaccine as described in the Materials and methods. On day 22 after tumor cell inoculation, tumor-draining lymph nodes and spleen were harvested to collected lymphocytes. (A-D) T-cells will be triple-stained with monoclonal antibodies against CD4, CD8 and Annexin-V or CD4, CD25 and Foxp3 to determine T-cell apoptosis and Tregs by flow cytometry, respectively. CD8 ${ }^{+}$CTLs were isolated from tumor-draining lymph nodes and then co-cultured with LLC cells at different ratios for 4 h. (E) LDH release assay was used to determine the cytotoxic activity of CTLs. ${ }^{*} \mathrm{P}<0.05$ and ${ }^{* *} \mathrm{P}<0.01$. IDO2, indoleamine 2,3-dioxygenase 2; DCs, dendritic cells.

inhibitory effects of the IDO2-silenced DC vaccine on tumor growth were more evident (Fig. 4B and C). At end point of observation (death or time elapse), excised tumor weight was measured. Tumor weight derived from the mice treated with IDO2 silenced DC was significantly lighter than the tumor from control DC-treated mice and non-treated mice (Fig. 4D). 
A

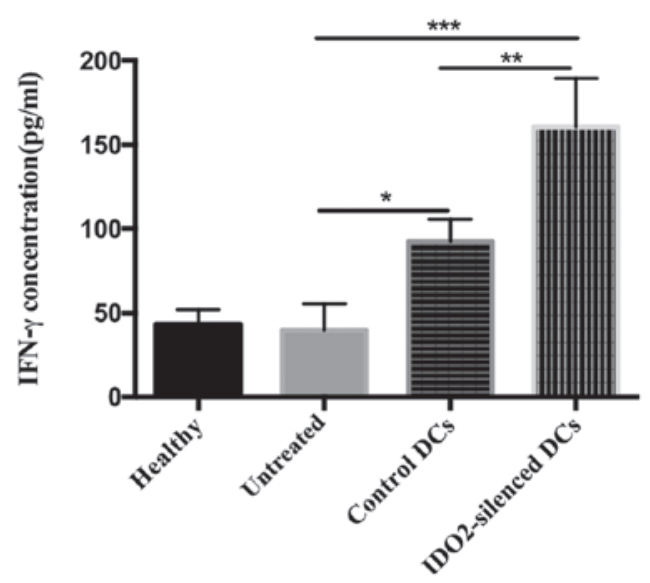

C

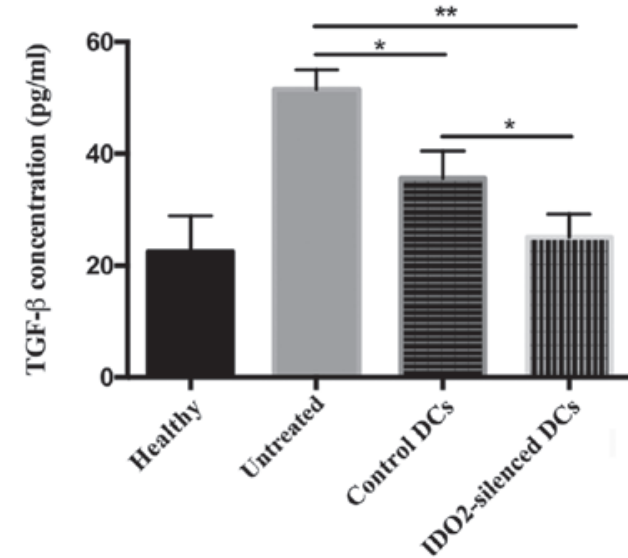

B

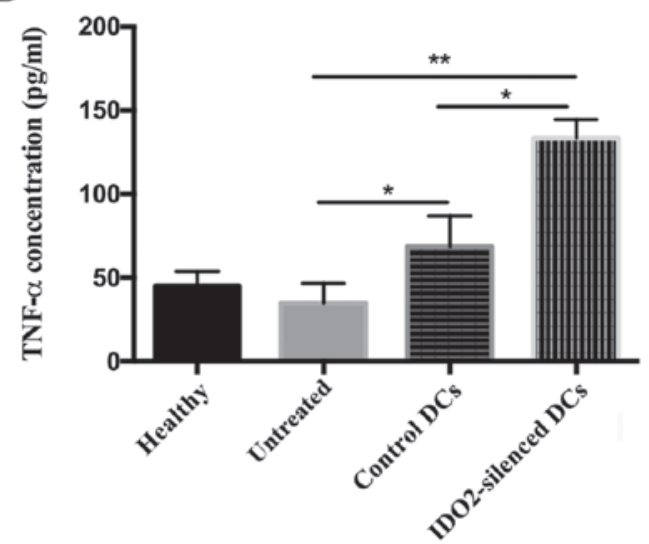

D

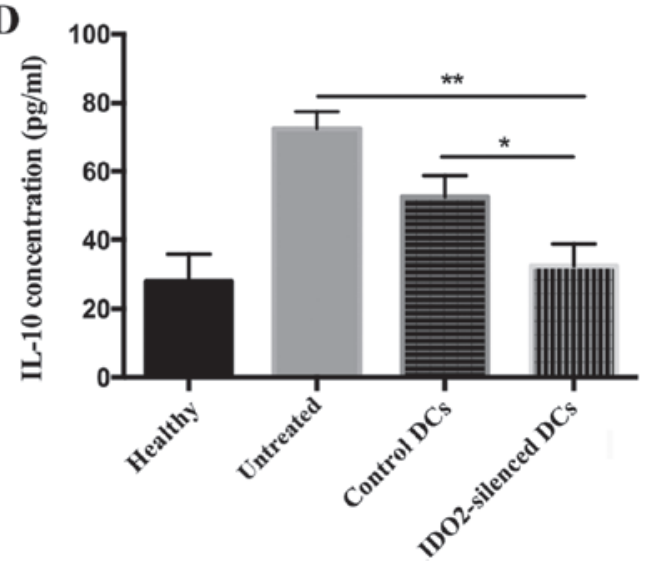

Figure 6. Treatment with IDO2-silenced DC-based tumor vaccine alters cytokine secretion profiles. Blood was collected from the differently treated mice at the end of the experiment and centrifuged to obtain serum. The concentration of (A) IFN- $\gamma$, (B) TNF- $\alpha$, (C) TGF- $\beta$ and (D) IL-10 in serum was determined by ELISA. ${ }^{*} \mathrm{P}<0.05,{ }^{* *} \mathrm{P}<0.01$ and ${ }^{* * *} \mathrm{P}<0.001$. IDO2, indoleamine 2,3-dioxygenase 2; DCs, dendritic cells; IFN- $\gamma$, interferon $\gamma$; TNF- $\alpha$, tumor necrosis factor $\alpha$; TGF- $\beta$, transforming growth factor $\beta$; IL-10, interleukin 10.

These results suggested that the IDO2-silenced DCs were a superior tumor vaccine, which displayed robust antitumor efficacy in suppressing LLC tumor growth.

IDO2-silenced DC-based tumor vaccine enhances the antitumor immune response. To characterize the mechanisms responsible for the enhanced antitumor activity mediated by the IDO2-silenced DCs, the apoptosis of T-cells, and Tregs from the tumor-draining lymph nodes or spleen from the tumor-bearing mice were analyzed. The results revealed that the IDO2-silenced DCs significantly decreased the number of apoptotic $\mathrm{CD}^{+}$ T-cells and apoptotic CD4+ T-cells (Fig. 5A and B). To examine the changes in the percentage of Tregs, FITC-labeled Foxp3, PE-labeled CD25 and Pecy5-labeled CD4 antibodies were used to stain the T-cells (Fig. 5C and D). Compared to the control DC-treated mice and untreated mice, the percentage of Tregs in the both spleen and lymph nodes from IDO2-silenced DC-treated mice exhibited a significant decrease which was close to that of the healthy mice. Furthermore, we examined the cytotoxic activity of $\mathrm{CD}^{+} \mathrm{T}$-cells by a CTL mediated tumor cell lysis assay. As shown in Fig. 5E, CD8 ${ }^{+} \mathrm{T}$-cells from the mice which were treated with the IDO2-silenced DC vaccine exhibited a higher lysis capacity than the CD8 ${ }^{+}$T-cells from the conventional DC vaccine-treated mice, suggesting that the IDO2-silenced DC vaccine induced stronger activities of CTLs against LLC cells. Taken together, these data demonstrated that the IDO2-silenced DC-based tumor vaccine enhanced the antitumor immune responses in the murine lung cancer model.

Treatment with IDO2-silenced DC-based tumor vaccine affects cytokine secretion profiles. To further explore the mechanisms responsible for the enhanced antitumor activity mediated by the IDO2-silenced DCs, at the end of the in vivo animal experiments, the tumor-bearing mice were sacrificed and serum was collected to determine the cytokine secretion profiles. Cytokines associated tumor progression (4 types) were selected and the levels of these were measured by ELISA. Compared with the control DC-treated mice and the untreated mice, the levels of IFN- $\gamma$ (Fig. 6A) and TNF- $\alpha$ (Fig. 6B) in the IDO2-silenced DC-treated mice were significantly increased by $>50 \%$, while the concentrations of TGF- $\beta$ (Fig. 6C) and IL-10 (Fig. 6D) were decreased. These data suggested that the IDO2-silenced DC-based tumor vaccine altered the secretion profiles that favor immune reaction against tumors.

\section{Discussion}

DCs are the most potent antigen presenting cells in the immune system. They interact with a number of immune cells in the immune response, whereas mature DCs can activate T-cells 
effectively. Theoretically speaking, as a therapeutic vaccine, DCs can produce more effective immune protection for cancer patients than other immune methods. However, the results of clinical studies have demonstrated that the effect of currently used DC tumor vaccines is not as potent as was originally expected; DC-based vaccines have produced disappointing results in clinical trials, despite being safe for clinical use $(34,35)$. Negating the function of immunosuppressive molecules may become an effective strategy with which to enhance the effectiveness of cancer vaccines (29). A novel mechanism of immunosuppression through IDO2 has recently attracted attention and has stimulated research in immunology (18,20-22,36-38). In the present study, it was demonstrated that the silencing of IDO2 gene in DCs increased DC-stimulated T-cell proliferation and reduced the induction of Tregs in vitro. Further in vivo experiments revealed that the IDO2-silenced DC-based tumor vaccine inhibited tumor growth and enhanced the antitumor immunity ability in a mouse model of lung cancer.

It has been reported that IDO2 is stably expressed in peripheral DCs and may contribute to the homeostatic tolerogenic capacity of DCs in healthy conditions (21). However, the expression of IDO2 in cultured DCs, as the initial step to establish the DC tumor vaccine, remains unclear. Therefore, the present study first determined the expression of IDO2 in the process of culture at both the mRNA and protein level. The results revealed that the expression of IDO2 increased gradually, peaking on the 7th day (Fig. 1A and B). DC-based vaccines for anticancer are usually utilized between days 5 to $7(39,40)$. Thus, the high expression of IDO2 may have a negative impact on the therapeutic efficacy. To further clarify the effects of IDO2 on DCs, gene interference was utilized to silence IDO2 gene expression in DCs and subsequently to implement a series of experiments. As was expected, the knockdown of IDO resulted in an enhanced immune response and antitumor effects.

DCs play a pivotal role in cancer immune responses. They induce adaptive immune responses by taking up, processing and presenting antigens to T-cells, and can be used as the basis of cancer vaccines (41). Indeed, the number of DCs in cancer patients decreases $(42,43)$ and this is usually a disorder of differentiation and maturation (44). It is well known that $\mathrm{CD}^{+}$ T-cells play a particularly important role in mediating the antitumor immune response and effector CTLs can directly kill cancer cells when recognizing tumor antigen, which is presented by DCs (45). Naturally, Foxp3 ${ }^{+}$Treg cells exist at a very low frequency in the tumor condition; however, an increase in the Foxp $3^{+}$Treg population has been reported and has been hypothesized to promote tumor tolerance (46). Thus, the ideal DC tumor vaccine should have the following characteristics: Efficient tumor antigen loading, a high expression of the costimulatory molecule, stimulating robust $\mathrm{T}$ lymphocyte proliferation, particularly $\mathrm{CD}^{+} \mathrm{T}$-cells and inducing fewer inhibitory T-cells. In the present study, to improve the efficiency of the DC-based cancer vaccine, IDO2 was silenced in DCs. For tumor antigen loading, the IDO2-silenced DCs were then challenged by LLC lysis for $24 \mathrm{~h}$ and then stimulated for maturation with TNF- $\alpha$. Notably, although IDO2 silencing did not alter the differentiation and maturity of DCs, the levels of the surface costimulatory molecules, CD40, CD80 and CD86, were upregulated in varying degrees when stimulated by tumor antigen and TNF- $\alpha$ (Fig. 2). In a mixed lymphocyte reaction, the IDO2-silenced DCs significantly increased $\mathrm{T}$ lymphocyte proliferation and reduced Treg cell induction (Fig. 3). Based on the above-mentioned ex vivo results, it was postulate that the IDO2-silenced DC-based tumor vaccine would possess a more potent antitumor capacity. To determine this, LLC lung cancer-bearing mice were treated with the IDO2-silenced DC vaccine. As was expected, compared to the untreated and control DC-treated group, the IDO2-silenced DCs suppressed tumor growth (Fig. 4) and induced a more potent antitumor immune response in the mouse model of lung cancer (Figs. 5 and 6).

IDO2 is expressed in primary cancer cells, as well as in DCs (47). It has been reported that the decomposition of tryptophan by IDO2 can induce the phosphorylation of eIF2A, a transcription initiation factor, to regulate cell proliferation and immune response. Although the enzymatic activities of IDO1 and IDO2 can both promote the upregulation of liver-enriched inhibitory protein (LIP), of note, the upregulation of LIP induced by IDO1 is reversed following tryptophan supplementation, while the upregulation of LIP induced by IDO 2 can not be reversed even after tryptophan supplementation. It has been speculated that IDO2 is closely related to tumor growth, invasion and distant metastasis (17). Another study found that in the co-culture system of T-cells and IDO2-overexpressing tumor cells, IDO2 expression inhibited the proliferation of $\mathrm{CD}^{+}{ }^{+} \mathrm{T}$-cells and $\mathrm{CD} 8^{+} \mathrm{T}$-cells, and the inhibition of $\mathrm{CD} 4^{+}$ $\mathrm{T}$ lymphocyte proliferation could not be reversed after increasing the tryptophan content (18). In human peripheral DCs, IDO2 is stably expressed in medullary and plasma DCs, and can induce Treg production (21). In IDO2 knockout mice, the number of Tregs induced by IDOl decreased significantly, indicating that IDO2 and IDO1 are interrelated in regulating immune homeostasis and IDO2 plays an immunosuppressive role in immune regulation (22). In the present study, it was demonstrated that the silencing of IDO2 expression in DCs more potently induced allogeneic T-cell proliferation in vitro. In addition, the utilization of the IDO2-silenced DC-based vaccine to challenge lung cancer-bearing mice decreased apoptotic $\mathrm{CD}^{+}{ }^{+} \mathrm{T}$-cells and $\mathrm{CD} 8^{+} \mathrm{T}$-cells in vivo. Furthermore, the knockdown of IDO2 in DCs decreased Treg generation and evoked enhanced antitumor effects.

In conclusion, the present study demonstrates that silencing the immunosuppressive gene, IDO2, in DCs ex vivo using siRNA may be an effective treatment strategy for lung cancer. The targeted silencing of IDO2 in DCs may prove to be a useful strategy with which to enhance antitumor immune responses and to improve the potential of immunotherapy to suppress tumor growth in cancer patients.

\section{Acknowledgements}

The authors are very grateful to Dr Hongmei Wang, Department of Immunology, Nanchang University, for providing assistance with performing the flow cytometry and analyzing the results.

\section{Funding}

The present study was partially supported by grants from the Natural Science Foundation of China (grant nos. 81673009 
and 81960113), the Jiangxi Natural Science Foundation (grant no. 20171BAB215082), the Science and Technology Project of Jiangxi Education Department (grant no. GJJ180966), the Science and Technology Plan of Jiangxi Health and Family Planning Commission (grant no. 20195664) and by the Canadian Institutes of Health Research (CIHR).

\section{Availability of data and materials}

All the datasets generated and analyzed in the present study are included in this published article.

\section{Authors' contributions}

YL and WM designed the study. HG, XC, HL, PX and CF performed the experiments. MT, YZ, YL and WM analyzed the data. YL and YZ wrote the manuscript, WM revised the manuscript. All authors read and approved the final manuscript.

\section{Ethics approval and consent to participate}

All animal experiments complied with the Regulations for the Administration of Affairs Concerning Experimental Animals of China and were approved by the Institutional Animal Care and Use Committee of Nanchang University, China.

\section{Patient consent for publication}

Not applicable.

\section{Competing interests}

The authors declare that they have not competing interests.

\section{References}

1. Hanahan D and Weinberg RA: Hallmarks of cancer: The next generation. Cell 144: 646-674, 2011.

2. Frumento G, Rotondo R, Tonetti M, Damonte G, Benatti U and Ferrara GB: Tryptophan-derived catabolites are responsible for inhibition of $\mathrm{T}$ and natural killer cell proliferation induced by indoleamine 2,3-dioxygenase. J Exp Med 196: 459-468, 2002.

3. De Vita F, Orditura M, Galizia G, Romano C, Lieto E, Iodice P, Tuccillo $C$ and Catalano G: Serum interleukin-10 is an independent prognostic factor in advanced solid tumors. Oncol Rep 7: 357-361, 2000.

4. Berghella AM, Pellegrini P, Del Beato T, Adorno D and Casciani CU: IL-10 and sIL-2R serum levels as possible periphera blood prognostic markers in the passage from adenoma to colorectal cancer. Cancer Biother Radiopharm 12: 265-272, 1997.

5. Orditura M, Romano C, De Vita F, Galizia G, Lieto E, Infusino S, De Cataldis $G$ and Catalano G: Behaviour of interleukin-2 serum levels in advanced non-small-cell lung cancer patients: Relationship with response to therapy and survival. Cancer Immunol Immunother 49: 530-536, 2000.

6. Kase H, Aoki Y and Tanaka K: Fas ligand expression in cervical adenocarcinoma: Relevance to lymph node metastasis and tumor progression. Gynecol Oncol 90: 70-74, 2003.

7. Sheehan KM, O'Donovan DG, Fitzmaurice G, O'Grady A, O'Donoghue DP, Sheahan K, Byrne MF, Conroy RM, Kay EW and Murray FE: Prognostic relevance of Fas (APO-1/CD95) ligand in human colorectal cancer. Eur J Gastroenterol Hepatol 15: 375-380, 2003

8. Gorter A and Meri S: Immune evasion of tumor cells using membrane-bound complement regulatory proteins. Immunol Today 20: 576-582, 1999.
9. Uyttenhove C, Pilotte L, Théate I, Stroobant V, Colau D, Parmentier N, Boon T and Van den Eynde BJ: Evidence for a tumoral immune resistance mechanism based on tryptophan degradation by indoleamine 2,3-dioxygenase. Nat Med 9: 1269-1274, 2003.

10. Muller AJ, DuHadaway JB, Donover PS, Sutanto-Ward E and Prendergast GC: Inhibition of indoleamine 2,3-dioxygenase, an immunoregulatory target of the cancer suppression gene Bin1, potentiates cancer chemotherapy. Nat Med 11: 312-319, 2005.

11. Friberg M, Jennings R, Alsarraj M, Dessureault S, Cantor A, Extermann M, Mellor AL, Munn DH and Antonia SJ: Indoleamine 2,3-dioxygenase contributes to tumor cell evasion of T cell-mediated rejection. Int J Cancer 101: 151-155, 2002.

12. Muller AJ and Prendergast GC: Marrying immunotherapy with chemotherapy: Why say IDO? Cancer Res 65: 8065-8068, 2005.

13. Munn DH and Mellor AL: IDO and tolerance to tumors. Trends Mol Med 10: 15-18, 2004.

14. Mellor AL and Munn DH: IDO expression by dendritic cells: Tolerance and tryptophan catabolism. Nat Rev Immunol 4: 762-774, 2004.

15. Puccetti P: On watching the watchers: IDO and type I/II IFN Eur J Immunol 37: 876-879, 2007.

16. Ball HJ, Sanchez-Perez A, Weiser S, Austin CJ, Astelbauer F, Miu J, McQuillan JA, Stocker R, Jermiin LS and Hunt NH: Characterization of an indoleamine 2,3-dioxygenase-like protein found in humans and mice. Gene 396: 203-213, 2007.

17. Metz R, Duhadaway JB, Kamasani U, Laury-Kleintop L, Muller AJ and Prendergast GC: Novel tryptophan catabolic enzyme IDO2 is the preferred biochemical target of the antitumor indoleamine 2,3-dioxygenase inhibitory compound D-1-methyl-tryptophan. Cancer Res 67: 7082-7087, 2007.

18. Qian F, Liao J, Villella J, Edwards R, Kalinski P, Lele S, Shrikant P and Odunsi K: Effects of 1-methyltryptophan stereoisomers on IDO2 enzyme activity and IDO2-mediated arrest of human $\mathrm{T}$ cell proliferation. Cancer Immunol Immunother 61: 2013-2020, 2012.

19. Yuasa HJ, Takubo M, Takahashi A, Hasegawa T, Noma H and Suzuki T: Evolution of vertebrate indoleamine 2,3-dioxygenases. J Mol Evol 65: 705-714, 2007.

20. Sun T, Chen XH, Tang ZD, Cai J, Wang XY, Wang SC and Li ZL: Novel 1-alkyl-tryptophan derivatives downregulate IDO1 and IDO2 mRNA expression induced by interferon-gamma in dendritic cells. Mol Cell Biochem 342: 29-34, 2010.

21. Trabanelli S, Očadlíková D, Ciciarello M, Salvestrini V, Lecciso M, Jandus C, Metz R, Evangelisti C, Laury-Kleintop L, Romero P, et al: The SOCS3-independent expression of IDO2 supports the homeostatic generation of $\mathrm{T}$ regulatory cells by human dendritic cells. J Immunol 192: 1231-1240, 2014.

22. Metz R, Smith C, DuHadaway JB, Chandler P, Baban B, Merlo LM, Pigott E, Keough MP, Rust S, Mellor AL, et al: IDO2 is critical for IDO1-mediated T-cell regulation and exerts a non-redundant function in inflammation. Int Immunol 26: 357-367, 2014.

23. O'Neill DW, Adams S and Bhardwaj N: Manipulating dendritic cell biology for the active immunotherapy of cancer. Blood 104: 2235-2246, 2004.

24. Iwashita Y, Goto S, Tominaga M, Sasaki A, Ohmori N, Goto T, Sato S, Ohta M and Kitano S: Dendritic cell immunotherapy with poly(D,L-2,4-diaminobutyric acid)-mediated intratumoral delivery of the interleukin-12 gene suppresses tumor growth significantly. Cancer Sci 96: 303-307, 2005.

25. Nestle FO, Alijagic S, Gilliet M, Sun Y, Grabbe S, Dummer R, Burg G and Schadendorf D: Vaccination of melanoma patients with peptide- or tumor lysate-pulsed dendritic cells. Nat Med 4: 328-332, 1998.

26. Liu Y, Zhang Y, Zheng X, Zhang X, Wang H, Li Q, Yuan K, Zhou N, Yu Y, Song N, et al: Gene silencing of indoleamine 2,3-dioxygenase 2 in melanoma cells induces apoptosis through the suppression of NAD+ and inhibits in vivo tumor growth. Oncotarget 7: 32329-32340, 2016.

27. Zheng X, Koropatnick J, Li M, Zhang X, Ling F, Ren X, Hao X, Sun H, Vladau C, Franek JA, et al: Reinstalling antitumor immunity by inhibiting tumor-derived immunosuppressive molecule IDO through RNA interference. J Immunol 177: 5639-5646, 2006.

28. Yujuan Z, Na S, Jiamin F, Yanling L, Xuelin Z, Shanshan P, Zhi Y, Xianfang Z, Yiguo C, et al: Synergic therapy of melanoma using GNRs-MUA- PEI/siIDO2-FA through targeted gene silencing and plasmonic photothermia. RSC 6: 79236-79237, 2016. 
29. Zheng X, Koropatnick J, Chen D, Velenosi T, Ling H, Zhang X, Jiang N, Navarro B, Ichim TE, et al: Silencing IDO in dendritic cells: A novel approach to enhance cancer immunotherapy in a murine breast cancer model. Int J Cancer 132: 967-977, 2013.

30. Zhang Y, Fu J, Shi Y, Peng S, Cai Y, Zhan X, Song N, Liu Y, Wang Z, et al: A new cancer immunotherapy via simultaneous DC mobilization and DC-targeted IDO gene silencing using an immune-stimulatory nanosystem. Int J Cancer 143: 2039-2052, 2018.

31. Zheng X, Vladau C, Zhang X, Suzuki M, Ichim TE, Zhang ZX, Li M, Carrier E, Garcia B, Jevnikar AM, et al: A novel in vivo siRNA delivery system specifically targeting dendritic cells and silencing CD40 genes for immunomodulation. Blood 113: 2646-2654, 2009.

32. Livak KJ and Schmittgen TD: Analysis of relative gene expression data using real-time quantitative PCR and the 2(-Delta Delta C(T)) Method. Methods 25: 402-408, 2001.

33. Banchereau J and Steinman RM: Dendritic cells and the control of immunity. Nature 392: 245-252, 1998.

34. Vacchelli E, Vitale I, Eggermont A, Fridman WH, Fučíková J, Cremer I, Galon J, Tartour E, Zitvogel L, Kroemer G, et al: Trial watch: Dendritic cell-based interventions for cancer therapy. OncoImmunology 2: e25771, 2013.

35. Galluzzi L, Senovilla L, Vacchelli E, Eggermont A, Fridman WH, Galon J, Sautès-Fridman C, Tartour E, Zitvogel L and Kroemer G: Trial watch: Dendritic cell-based interventions for cancer therapy. OncoImmunology 1: 1111-1134, 2012.

36. Sørensen RB, Køllgaard T, Andersen RS, van den Berg JH, Svane IM, Straten P and Andersen MH: Spontaneous cytotoxic T-Cell reactivity against indoleamine 2,3-dioxygenase-2. Cancer Res 71: 2038-2044, 2011

37. Køllgaard T, Klausen TW, Idorn M, Holmgaard RB, Straten PT and Andersen $\mathrm{MH}$ : Association of a functional Indoleamine 2,3-dioxygenase 2 genotype with specific immune responses. OncoImmunology 1: 441-447, 2012.
38. Merlo LMF, Pigott E, DuHadaway JB, Grabler S, Metz R, Prendergast GC and Mandik-Nayak L: IDO2 is a critical mediator of autoantibody production and inflammatory pathogenesis in a mouse model of autoimmune arthritis. J Immunol 192: 2082-2090, 2014.

39. Baek S, Lee SJ, Kim MJ and Lee H: Dendritic cell (DC) vaccine in mouse lung cancer minimal residual model; Comparison of monocyte-derived DC vs. hematopoietic stem cell derived-DC. Immune Netw 12: 269-276, 2012.

40. Hsu YL, Huang MS, Cheng DE, Hung JY, Yang CJ, Chou SH and Kuo PL: Lung tumor-associated dendritic cell-derived amphiregulin increased cancer progression. J Immunol 187: 1733-1744, 2011.

41. Gardner A and Ruffell B: Dendritic cells and cancer immunity. Trends Immunol 37: 855-865, 2016.

42. Ghirelli C, Reyal F, Jeanmougin M, Zollinger R, Sirven P, Michea P, Caux C, Bendriss-Vermare N, Donnadieu MH, Caly $\mathrm{M}$, et al: Breast cancer cell-derived GM-CSF licenses regulatory Th2 induction by plasmacytoid predendritic cells in aggressive disease subtypes. Cancer Res 75: 2775-2787, 2015.

43. Xi HB, Wang GX, Fu B, Liu WP and Li Y: Survivin and PSMA loaded dendritic cell vaccine for the treatment of prostate cancer. Biol Pharm Bull 38: 827-835, 2015.

44. Hossain DM, Dos Santos C, Zhang Q, Kozlowska A, Liu H, Gao C, Moreira D, Swiderski P, Jozwiak A, Kline J, et al: Leukemia cell-targeted STAT3 silencing and TLR9 triggering generate systemic antitumor immunity. Blood 123: 15-25, 2014.

45. Fu C and Jiang A: Dendritic cells and CD8 T cell immunity in tumor microenvironment. Front Immunol 9: 3059, 2018

46. Koos D, Josephs SF, Alexandrescu DT, Chan RC, Ramos F, Bogin V, Gammill V, Dasanu CA, De Necochea-Campion R, Riordan NH, et al: Tumor vaccines in 2010: Need for integration. Cell Immunol 263: 138-147, 2010.

47. Lob S, Konigsrainer A, Schafer R, Rammensee HG, Opelz G and Terness P: Levo- but not dextro-1-methyl tryptophan abrogates the IDO activity of human dendritic cells. Blood 111: 2152-2154, 2008. 